Published in final edited form as:

Addict Behav. 2010 February ; 35(2): 102-110. doi:10.1016/j.addbeh.2009.09.009.

\title{
Cannabis dependence in the San Francisco Family Study: age of onset of use, DSM-IV symptoms, withdrawal, and heritability
}

\author{
Cindy L. Ehlers ${ }^{b}$, lan R. Gizer ${ }^{a}$, Cassandra Vieten ${ }^{c}$, David A. Gilder ${ }^{b}$, Gina M. Stouffer ${ }^{b}$, Philip \\ Lau $^{b}$, and Kirk C. Wilhelmsen ${ }^{a}$ \\ aDepartment of Neurology and Genetics and the Bowles Center for Alcohol Studies, University of \\ North Carolina, 4109 Neurosciences Research Bldg, CB\#7264, Chapel Hill, NC 27599, USA
}

bDepartment of Molecular and Integrative Neurosciences, The Scripps Research Institute, 10550 North Torrey Pines Road, SP30-1501, La Jolla, CA 92037, USA

'California Pacific Medical Center Research Institute, 2200 Webster Street, Rm. 514, San

Francisco, CA 94115, USA.

\begin{abstract}
Cannabis is the most widely used illicit drug in the United States, yet the role of genetics in individual symptoms associated with cannabis use disorders has not been evaluated. The purpose of the present set of analyses was to describe the symptomatology and estimate the heritability of DSM-IV criteria/ symptoms of cannabis dependence in a large sample of families. Participants were 2524 adults, participating in the University of California San Francisco (UCSF) Family Study of alcoholism. Seventy percent of the sample had ever used cannabis and $13.9 \%$ met DSM-IV criteria for cannabis dependence. Younger age at first cannabis use was found to be significantly associated with a shortened survival to becoming cannabis dependent. Although a greater percentage of men met criteria for cannabis dependence, women were found to demonstrate "telescoping" as indexed by a shorter survival time from initial use to dependence as compared to men. A cannabis withdrawal syndrome was identified in users, the primary symptoms of which were nervousness, appetite change, and sleep disturbance. Cannabis use $\left(\mathrm{h}^{2}=0.31\right)$ and dependence $\left(\mathrm{h}^{2}=0.20\right)$, age at first use, individual DSM-IV criteria for dependence, and cannabis-use associated symptoms of depression, trouble concentrating and paranoia were all found to be heritable. These findings suggest that within this population that cannabis use and dependence, as well as individual cannabis dependence symptoms have a significant heritable component, that cannabis dependence is more likely to occur when use
\end{abstract}

(C) 2009 Elsevier Ltd. All rights reserved.

Corresponding Author: Dr. C.L Ehlers, The Scripps Research Institute, 10550 North Torrey Pines Road, SP30-1501, La Jolla, CA 92037. Telephone: (858) 784-7058, Fax: (858) 784-7409, cindye@ scripps.edu.

Publisher's Disclaimer: This is a PDF file of an unedited manuscript that has been accepted for publication. As a service to our customers we are providing this early version of the manuscript. The manuscript will undergo copyediting, typesetting, and review of the resulting proof before it is published in its final citable form. Please note that during the production process errors may be discovered which could affect the content, and all legal disclaimers that apply to the journal pertain.

\section{Contributors}

The submitted manuscript has been read and approved by all authors and all authors concur with the submitted manuscript. Kirk Wilhelmsen and Cassandra Vieten designed the study and wrote the protocol. Phillip Lau, Gina Stouffer and Ian Gizer conducted the statistical analysis. David Gilder did all best final diagnoses of research participants. Cindy Ehlers wrote the first draft of the manuscript and all authors contributed to and have approved the final manuscript. In addition, the authors acknowledge that they have exercised due care in ensuring the integrity of the work, and none of the original material contained in the manuscript has been submitted for consideration nor will any of it be published elsewhere except in abstract form in connection with scientific meetings.

Conflict of Interest

None of the authors have any conflict of interest related to material presented in the manuscript 
begins during adolescence, and that the cannabis dependence syndrome includes a number of heritable untoward psychiatric side effects including withdrawal.

\section{Keywords}

Age of onset; Cannabis dependence; Cannabis Withdrawal; Gender; Heritability

\section{Introduction}

\subsection{Prevalence of cannabis use disorders and its association with physical and mental health problems}

National epidemiological samples have demonstrated that cannabis is the most commonly used illicit drug (Anthony, Warner \& Kessler, 1994; Stinson et al., 2005; Stinson, Ruan, Pickering $\&$ Grant, 2006), and that its use has substantially increased over the last decade (Compton, Grant, Colliver, Glantz \& Stinson, 2004). The prevalence of dependence on cannabis in the United States appears to be higher than any other illicit drug. The 2003 National Survey on Drug Use and Health (Substance Abuse and Mental Health Services Administration [SAMHSA], 2003) reported that $40.6 \%$ of the U.S. population had used cannabis or hashish during their lifetime and that 4.2 million individuals age 12 years and older met criteria for past year cannabis abuse or dependence using DSM-IV (American Psychiatric Association, 1994) criteria. Lifetime rates of cannabis dependence in the National Epidemiologic Survey of Alcohol and Related Conditions (NESARC) were reported to be $1.3 \%$, rates of $1.8 \%$ were found in the National Longitudinal Alcohol Epidemiologic Study (NLAES) and 4.2\% in the National Co-morbidity study (NCS) (see Anthony et al., 1994; Compton et al., 2004).

Chronic use of cannabis is associated with both physical and mental health problems. Persistent use poses health problems similar to those of tobacco (Fisher, Ghuran, Vadamalai \& Antonios, 2005; Hashibe et al., 2005; Mittleman, Lewis, Maclure, Sherwood \& Muller, 2001; Tashkin, 2005; Taylor, Poulton, Moffitt, Ramankutty \& Sears, 2000). Cannabis use has also been implicated in a syndrome characterized by apathy, loss of goal-directed behavior, and cognitive impairment termed the "amotivational syndrome" (Pope, Gruber, Hudson, Huestis \& Yurgelun-Todd, 2001; Schuckit, 2006; Sharma, 1975; Solowij et al., 2002). Cannabis use is associated with psychotic illness and depression (Degenhardt, Hall \& Lynskey, 2003; Hall, Degenhardt \& Teesson, 2004), as well as impaired educational and work performance (Kandel \& Chen, 2000; Lynskey \& Hall, 2000; Schuckit, 2006; Swift, Hall \& Teesson, 2001). Early use of cannabis is associated with a higher likelihood of developing cannabis dependence (Chen, Storr \& Anthony, 2009; Ehlers, Slutske, Gilder, Lau \& Wilhelmsen, 2006; Swift, Coffey, Carlin, Degenhardt \& Patton, 2008). Use of cannabis, particularly by adolescents and young adults, may also facilitate progression to other illicit drug use (the "gateway" drug hypothesis) (Behrendt, Wittchen, Höfler, Lieb \& Beesdo, 2009; Degenhardt et al., 2009; Fergusson \& Horwood, 2000; Lynskey et al., 2003).

\subsection{Genetic influences on cannabis use and use disorders}

Twin and family studies have consistently found that cannabis use disorders appear to have a genetic component (for review see Agrawal \& Lynskey, 2006). Correlations between parents and offspring and between siblings typically range from 0.3-0.6 (Bierut et al., 1998; Gfroerer, 1987; Hopfer, Stallings, Hewitt \& Crowley, 2003; Meller, Rinehart, Cadoret \& Troughton, 1988; Merikangas et al., 1998) for cannabis use. Twin studies of cannabis use have reported heritability estimates that ranging from 0.17 to 0.67 , whereas studies that have evaluated the role of genetic and environmental risk factors on cannabis abuse or cannabis dependence in twin samples have found significantly higher estimates of heritability (estimates range from 
0.45 to 0.78) (see Kendler \& Prescott, 1998; Kendler, Karkowski, Neale \& Prescott, 2000; Maes et al., 1999; McGue, Elkins \& Iacona, 2000; Miles et al., 2001; Rhee et al., 2003; Tsuang et al., 1998; van den Bree et al., 1998).

DSM-IV requires that three out of six groups of symptoms must be present to make a diagnosis of cannabis dependence (American Psychiatric Association, 1994), so theoretically a number of different symptom combinations could lead to a diagnosis. Evaluation of data from the NESARC suggests that cannabis dependence appears to be a highly heterogeneous disorder and does present in a diverse set of symptom combinations (Blanco et al., 2008). One interpretation of these findings is that cannabis use directly and independently affects a variety of behaviors indexed by the dependence criteria but that individual vulnerability may influence which symptoms are actually expressed. If this theory is correct, then it may be further posited that different symptoms or clusters of symptoms may have a unique genetic or environmental basis. For instance, a number of studies have reported that cannabis "craving" is one of the most common symptoms reported during withdrawal and that it significantly contributes to failed quit attempts (see Budney, Novy \& Hughes, 1999; Budney, Vandry, Hughes, Thostenson \& Bursac, 2008; Cornelius, Chung, Martin, Wood \& Clark, 2008; Heishman et al., 2009; McRae, Hedden, Malcolm, Carter \& Brady, 2007) Recent data suggest that a history of parental alcohol/drug problems is associated with an increased likelihood of experiencing cannabis withdrawal, suggesting that it may in part be heritable (Agrawal et al., 2008a). While the clinical symptomatology of cannabis use and cannabis dependence have been previously described in large nationwide epidemiological studies and cannabis dependence has been shown to be heritable, to date, genetic analyses of individual DSM-IV cannabis dependence criteria/ symptoms and cannabis induced symptomatolgy, such as withdrawal and craving, has not been published.

\subsection{The present study}

The goals of the present study were to describe the prevalence of a number of clinical symptoms associated with use of cannabis in this population in men and women and to estimate the heritability of: cannabis use, cannabis dependence, as well as the individual DSM-IV criteria and other symptoms associated with cannabis dependence using the University of California San Francisco (UCSF) Family Study of alcoholism dataset. Specifically the prevalence of cannabis use and its transition to dependence, the prevalence of each of the DSM-IV cannabis dependence criteria and cannabis-induced psychiatric symptoms, such as craving, depression, trouble concentrating, psychotic symptoms as well as the extent to which cannabis users experiences symptoms of withdrawal and seek treatment was evaluated. The heritability of cannabis use, DSM-IV cannabis dependence and individual criteria/symptoms of cannabis dependence and cannabis-induced symptomatology was also estimated.

The UCSF Family Alcoholism Study is a project that was designed to identify genetic loci that influence susceptibility to alcohol dependence and related phenotypes. It used a small family design, focusing primarily on sibling pairs and parent-child trios. The study enrolled 2454 individuals from 970 families from December 1995 through January 2003. Test-retest and inter-rater reliability for clinical data have been shown to be very good. Design, methods, and sample demographics of the UCSF Family Alcoholism Study have been presented previously (see Seaton, Cornell, Wilhelmsen \& Vieten, 2004; Vieten, Seaton, Feiler \& Wilhelmsen, 2004), along with intrafamilial correlations for primary diagnostic phenotypes. 


\section{Methods}

\subsection{Participants and recruitment}

The UCSF Family Study is a behavioral genetics study that recruited probands with alcohol dependence and the relatives of those probands, nationwide. In addition, a community sample was ascertained in order to estimate population means and standard deviations for heritability and linkage analyses. Participants were recruited through the use of semi-targeted direct mail, a web site, press releases, and advertisements, and from alumni of treatment centers across the nation. Thirty-three percent of the probands were recruited from the general population random mailings, $32 \%$ from community organizations, $18 \%$ from treatment program alumni, and 17 $\%$ from other sources. Probands reporting serious drug dependence (defined as use of stimulants, cocaine, or opiates daily for more than 3 months or weekly for more than 6 months), current or past diagnosis of schizophrenia, bipolar disorder, or other psychiatric illness involving psychotic symptoms, a life-threatening illness, or an inability to speak and read English were excluded. The details of recruitment of all participants have been previously published (see Seaton et al., 2004; Veiten et al., 2004)

\subsection{Measures of assessment}

A remote data collection procedure was developed allowing for blood samples for genotyping and other questionnaires to be returned by mail, and structured diagnostic interviews to be conducted by telephone, making nationwide data collection possible. Potential participants first had the study explained and gave written informed consent. A modified version of the Semi-Structured Assessment for the Genetics of Alcoholism (SSAGA) (Bucholz, et al., 1994) was used to collect demographic, medical, psychiatric, alcohol, nicotine, and other drug use history. The SSAGA is a fully structured, poly-diagnostic psychiatric interview that has undergone both reliability and validity testing. Modifications of the SSAGA for the UCSF study included changes in diagnostic criteria and items to obtain DSM-IV criteria. Only the sections of the SSAGA relevant to substance abuse, demographics and medical history were utilized. The SSAGA uses a criterion of having used cannabis 21 times in a single year as a cut off for assessing the full range of use, abuse and dependence symptoms. Twenty percent of those enrolled did not complete all study requirements. Only limited data were available for non-completers, but follow-up analyses suggested that participants failing to complete the study were more likely to be male (chi-square $=5.18, \mathrm{p}=.025$ ), and to use marijuana (chi-square $=27.06, \mathrm{p}<.001)$ Details of the interview process and inter-rater reliability of the SSAGA, and complete demographic information in this study have been reported previously (Vieten et al., 2004).

\subsection{Statistical data analyses and estimates of heritability}

The data analyses were based on the specific aims, the first aim of which was to describe the full range of clinical symptomatology associated with cannabis use and dependence in the UCSF Family Study population in men and women. These analyses allowed us to compare clinical data to other large epidemiological samples drawn from a general population sample as well as to identify variables that were present to a large enough extent in this population to be suitable for heritability analyses. The first set of analyses evaluated the prevalence of, and transitions from use to dependence in men and women in this sample. To accomplish these analyses the transitions between the number of participants that endorsed: having ever tried cannabis, having used at least 21 times in a single year (a cut off for estimating cannabis symptomatology using the SSAGA), and having three DSM-IV symptom groups of dependence were tallied and potential gender differences in these variables were calculated, using chi-square. The conditional probabilities of the transitions from use to used 21 times and from used 21 times to dependence were also estimated. This was accomplished by: (1) dividing the number of participants who had used 21 times by the number of participants who had used, 
and (2) dividing the number of participants who had developed dependence by the number of participants who had used 21 times, using the method described in Tsuang et al., (1999).

Potential gender differences in the conditional probabilities of transition were calculated using the test statistic for two proportions. The co-morbidity of cannabis dependence with alcohol dependence was also estimated.

The second set of analyses on the clinical dataset were conducted in order to determine whether a significant association exists between age at first use and the presence of cannabis dependence in this population, as has been seen in other populations. To test this hypothesis, the trajectory between age of onset of first cannabis use and transition to cannabis dependence was determined using survival analyses. The Kaplan-Meier method was used to estimate survival time using a time to event model (time interval from first use to dependence) in the presence of censored cases. Therefore, the age of onset of first use was used as the initial variable to: (1) determine its association with cannabis dependence, and (2) to estimate the duration of time elapsed between first use and the onset of dependence in the survival analyses.

The third set of analyses of the clinical dataset were conducted to determine the prevalence of each of the DSM-IV cannabis dependence criteria/symptoms as well as other cannabis-induced psychiatric symptoms, the extent to which cannabis users experiences symptoms of withdrawal, and the types of treatment options participants had sought. To accomplish these analyses the data were tallied and potential gender differences in these variables calculated using chi-square.

The second overall aim of the study was to determine the heritability of cannabis use, DSMIV cannabis dependence and the individual criteria/symptoms of dependence as well as "craving" (defined as: "in situations where you couldn't use marijuana, did you ever have such a strong desire for it that you couldn't think of anything else?"), and cannabis withdrawal using a family genetics design. Two thousand five hundred and twenty-two individuals from 890 pedigrees were included in the heritability analyses. The proportion of phenotypic variation that is genetic assuming a simple additive model was estimated for the traits. The total additive genetic heritability $\left(\mathrm{h}^{2}\right)$ that represents the proportion of variation in the phenotype that is due to genetic influences, and its standard error, were estimated using SOLAR v 2.0.4 (Almasy \& Blangero, 1998; Southwest Foundation of Biomedical Research [S.F.B.R], 2009). SOLAR estimates heritability by partitioning the trait relative pair covariance into additive genetic and environmental contributions. It should be noted that SOLAR relies on the inclusion of relative pairs living apart to disentangle genetic and shared environmental influences. The UCSF Family Study sample consists of 563 parent-child, 1085 sibling, 40 half sibling, 17 grandparentgrandchild, 238 avuncular, and 32 cousin relative pairs that are genetically informative. This combination of small and extended pedigrees provides some protection against the conflation of additive genetic and shared environmental influences. Nonetheless, it should be noted that without the inclusion of monozygotic twin pairs, these two sources of variation cannot be perfectly disentangled, and a positive bias in heritability estimates can occur.

For all heritability analyses, subject's age at the time of evaluation and gender were included as potential covariates and retained if they accounted for at least $5 \%$ of the total variance in the phenotype. The dichotomous traits were modeled as quantitative rather than using the liability threshold model for discrete traits. It has been documented that this approach yields more conservative estimates of heritability, and thus, this approach was used to further ensure that the reported heritability estimates for the analyzed phenotypes were not positively biased. Because the current sample was selected for alcohol dependence, it was also necessary to correct for potential ascertainment biases. Collecting a sample selected for a specific disorder frequently reduces the observed variation in the selected trait due to the over-sampling of individuals at the high end of the distribution. In quantitative genetic analyses, this reduced 
variation can result in negatively biased estimates of heritability necessitating the inclusion of methods to correct for such ascertainment bias. One such method is to constrain the sample mean of the trait of interest to that observed in the general population. Simulation analyses using SOLAR have suggested that this approach can be used to correct for such ascertainment bias (Blangero, unpublished data as cited in Cripe, Andelfinger, Martin, Shooner \& Benson, 2004), and thus, the mean prevalence rate for the cannabis dependence diagnosis was constrained to the prevalence rate found in the UCSF control sample (i.e., 0.071) to correct for ascertainment bias when estimating $\mathrm{h}^{2}$ for this diagnosis. Similarly, the prevalence rates for each of the cannabis dependence symptoms were estimated in this control sample and used to correct for any ascertainment bias when estimating $\mathrm{h}^{2}$ for those symptoms. Further details regarding these methods have been described previously (Ehlers, Wall, Betancourt \& Gilder, 2004, Ehlers et al., 2006; Wilhelmsen \& Ehlers, 2005).

\section{Results}

\subsection{Demographics}

The demographic characteristics of this population have been presented previously (see Vieten et al., 2004). In brief, the UCSF family sample $(n=2377)$ had a mean age of $48.4 \pm 13.4$ years, a mean educational level of $14.4 \pm 2.9$ years, and an annual income of $\$ 57,356 \pm \$ 54,656$. Racial distribution was: 92\% Caucasian, 3\% each African American and Hispanic, and 1\% each Native American and Other. Fifty-four percent were married. The sample was ascertained to collect families with alcohol dependence from the community. Probands in this study were $58 \%$ female, with $97 \%$ of probands meeting lifetime criteria for alcohol dependence, whereas, $38 \%$ of the relatives of probands were found to be alcohol dependent. The control sample $(\mathrm{n}=147)$ had similar demographic characteristics to the Family Study sample with $92 \%$ being Caucasian, $58 \%$ being female, a mean age of 51.2 years, a mean income of $\$ 48,947$, and a mean education level of 14.0 yrs and with $15 \%$ having a lifetime history of DSM-IV alcohol dependence and $7 \%$ a lifetime history of cannabis dependence.

\subsection{Prevalence of cannabis use and use disorders in the SF Family Study population}

As seen in table 1, 70\% ( $\mathrm{n}=1764)$ of the SF Family Study population had "tried" cannabis at least once in their life. There were an equivalent number of males and females in the population that had reported using the drug. Approximately, forty-five percent $(44.9 \%, \mathrm{n}=818)$ of the population has used cannabis greater than 21 times in a single year, and among those participants using cannabis at that level or greater, significantly more were men than women ( chi square $=25.98, \mathrm{df}=1, \mathrm{p}<0.0001)$. Approximately fourteen percent $(13.9 \%, \mathrm{n}=349)$ of the study population had a lifetime diagnosis of DSM-IV cannabis dependence and within this group significantly more were men (chi-square $=20.04, \mathrm{df}=1, \mathrm{p}<0.0001$ ). The conditional probability of: (1) transitioning from reporting having used cannabis to having used at least 21 times in a single year; and (2) transitioning from reporting having used at least 21 times in a single year to meeting criteria for cannabis dependence was calculated for the entire sample and for men and women separately (see table 1). Men were significantly more likely than women to transition from use to used 21 times $(\mathrm{z}=5.29 ; \mathrm{p}<0.000001)$, as well as to transition from used 21 times to dependence $(\mathrm{z}=2.13 ; \mathrm{p}<0.03)$. Lifetime diagnosis of DSM-IV cannabis dependence was also found to be significantly co-morbid with a lifetime diagnosis of alcohol dependence (chi-square $=117.6, \mathrm{df}=1, \mathrm{p}<0.00001$ ).

\subsection{Effect of age at first cannabis use on the development of cannabis dependence}

The mean ( \pm S.D.) age of first cannabis use was $19.92( \pm 8.55)$, and the mean age of cannabis dependence was 28.28 ( \pm 9.32$)$. There were no significant differences between men and women on mean age of onset of first cannabis use as estimated by survival to first cannabis use (Mantel Cox Chi-Square $=0.017, \mathrm{df}=1, \mathrm{p}=\mathrm{NS}$ ). Survival analyses did, however, reveal that having a 
lifetime cannabis dependence diagnosis was significantly associated with the age at which a person reported first trying the drug. Figure 1 graphically represents the survival curves for: ages $<13$ vs. 13 or greater, $<15$ vs. 15 or greater, $<17$ vs. 17 or greater, $<19$ vs. 19 or greater, $<21$ vs. 21 or greater and $<25$ vs. 25 or greater, which were generated using the Kaplan-Meier method. These survival curves were compared at each of the ages using the log-rank test of the null hypothesis of a single survival curve. Significant differences $(p<0.001)$ were found for each age as seen in table 2. The actual survival time from first use to meeting criteria for DSM-IV cannabis dependence was also compared for each age as indicated above using t-tests and significant differences ( $\mathrm{p}<0.0001)$ were found for: $<13$ vs. 13 or greater, $<15$ vs. 15 or greater, $<17$ vs. 17 or greater, $<19$ vs. 19 or greater. Having tried cannabis at 13 or younger was found to be associated with a mean survival time to cannabis dependence of $27.2 \pm 2.2$ years as opposed to $43.1 \pm 0.5$ years for individuals who did not try the drug until after the age of 25. Overall survival time for the population was also found to be significantly different based on gender $(\mathrm{t}=-3.756 ; \mathrm{p}<0.0001)$, with women demonstrating a shorter survival time (44.07 \pm $0.6 \mathrm{yrs})$ than men $(49.3 \pm 1.3 \mathrm{yrs})$.

\subsection{Clinical symptoms resulting from cannabis use in the UCSF Family Study}

Table 3 gives the prevalence of each of the DSM-IV cannabis dependence criteria/symptoms in the portion of the population that had endorsed having ever taken cannabis at least 21 times in a single year. The most commonly endorsed cannabis dependence symptom found in this group of individuals was "continued to use marijuana despite emotional or psychological problems". The second most common dependence symptom was: "great deal of time spent obtaining, using, or recovering from marijuana". The prevalence of only two symptoms differed between men and women: (1) "great deal of time spent obtaining, using, or recovering from marijuana" and (2) tolerance. Of those participants who had used cannabis more than 21 times in a single year, $16.6 \%(\mathrm{n}=135)$ endorsed having experienced cannabis withdrawal and $16.0 \%(\mathrm{n}=130)$ reported using cannabis to avoid withdrawal. There were no gender differences in the number of participants that endorsed cannabis withdrawal. Of those participants who had experienced withdrawal, as seen in table 4, the most common symptom of withdrawal endorsed was feeling "nervous, tense, restless or irritable". The second and third most common symptoms of withdrawal were "appetite change or weight change" and "trouble sleeping". Participants in the study who had taken cannabis more than 21 times in a single year also reported experiencing a number of other psychiatric symptoms associated with that use that lasted more than 24 hours, as seen in table 4 . Within the group of participants who had endorsed using cannabis more than 21 times in a single year $29.1 \%(\mathrm{n}=231)$ reported having experienced depression or disinterest in things, $32.8 \%(\mathrm{n}=261)$ had reported being paranoid or suspicious of people and $17.9 \%(n=142)$ had experienced hallucinations for more than a 24 hour period.

Of those who had used cannabis more than 21 times in a single year 36.6\% $(\mathrm{n}=292)$ reported that they wanted to stop using the drug, and $21 \%(\mathrm{n}=167)$ reported having actually tried to stop using cannabis but could not. Within the group of participants who had endorsed using cannabis more than 21 times $17.9 \%(\mathrm{n}=142)$ reported ever bringing up any problems they might have had with cannabis with any professional including a member of the clergy.

\subsection{Heritability analyses of cannabis use, use disorders and cannabis symptomatology}

Table 5 lists the findings of the heritability analyses. Having ever tried cannabis $\left(\mathrm{h}^{2}=0.52\right.$, $\mathrm{p}<0.0001)$, having used it at least 21 times in a single year $\left(\mathrm{h}^{2}=0.31, \mathrm{p}<0.0001\right)$, and DSMIV cannabis dependence $\left(\mathrm{h}^{2}=0.20, \mathrm{p}<0.0001\right)$ were all found to be significantly heritable. Additionally, age at first cannabis use was also found to be heritable $\left(\mathrm{h}^{2}=0.22, \mathrm{p}<0.002\right)$. When heritability was estimated for DSM-IV cannabis dependence criteria/symptoms, individually, all the symptoms were found to be significantly heritable $\left(\mathrm{h}^{2}=0.10-0.29, \mathrm{p}<0.01\right)$. In addition, several untoward symptoms that participants reported experiencing for more than 24 hours 
were also found to be significantly heritable such as: depression $\left(h^{2}=0.16, \mathrm{p}<0.001\right)$, trouble concentrating $\left(\mathrm{h}^{2}=0.19, \mathrm{p}<0.0001\right)$ and paranoia $\left(\mathrm{h}^{2}=0.11, \mathrm{p}<0.007\right)$. Additionally, two of the symptoms that had the highest heritability were cannabis craving $\left(\mathrm{h}^{2}=0.36, \mathrm{p}<0.0001\right)$ and nervousness during cannabis withdrawal $\left(\mathrm{h}^{2}=0.28, \mathrm{p}<0.001\right)$

\section{Discussion}

\subsection{Clinical symptoms associated with cannabis use in the San Francisco Family Study: differences between in men and women}

Cannabis is the most widely used illicit substance in the United States and world-wide (Hall \& Degenhardt, 2007; Maxwell, 2008). The prevalence of lifetime DSM-IV cannabis dependence in the UCSF Family Study was elevated (13.9\%) compared to the general population but was similar to what has been reported for other high risk samples such as the Collaborative Study of the Genetics of Alcoholism (COGA) where 20\% of the genotyped sample was found to have a lifetime diagnosis of cannabis dependence (Agrawal et al., 2006). Gender differences in cannabis use, abuse, and dependence are a consistent finding in the literature (see Grant \& Pickering, 1998; McCrady \& Epstein, 1999; Stinson et al., 2006). This was also found to be true in the UCSF Family Study where although equivalent numbers of men and women in the UCSF Family Study reported having used cannabis a significantly higher proportion of men endorsed having used it 21 times or more in a single year and more men than women met DSM-IV criteria for cannabis dependence.

Although a number of studies have demonstrated that cannabis use and dependence are more common in men fewer studies have evaluated gender differences in the probability of becoming dependent once use has begun. In a comparison of 6 illicit drugs/classes of drugs (cannabis, amphetamine, cocaine, sedatives, heroin, psychedelics), Tsuang et al. (1999) found, using data from the Vietnam Era Twin Registry (VETR), that cannabis had the highest conditional probability for the transition from exposure to use ( 0.57$)$, from use to use more than five times (0.44), and from use more than five times to regular use (0.70). The conditional probability of transition from regular use of cannabis to cannabis use disorders was 0.33 in the VETR study. However, the VETR study only evaluated male-male twins and thus information for female users was not available. In the present study, conditional probabilities for transition from use to used 21 times (0.46) and from used 21 times to dependence (0.43) were similar to the ranges found in the VETR study; however, in the UCSF study we were able to compare probabilities between men and women and discovered that men had significantly higher probabilities of transition between the different stages of use. This finding confirms previous studies in an American Indian population where men (0.57) were significantly more likely than women (0.26) to transition from initiation of cannabis use to dependence (Ehlers et al., 2007). Data from the National Comorbidity survey have also demonstrated that men had a higher risk of developing cannabis dependence two years after initial use than women (Wagner \& Anthony, 2007). Taken together these data suggest that cannabis may be more "addicting" to men than women in the populations thus far evaluated.

In the UCSF Family Study there were no significant differences between men and women on mean age of onset of cannabis use. However, survival analyses of the UCSF family population revealed that those participants who began using cannabis at younger ages had significantly different survival curves of use to dependence than those who began at a later age. These data are consistent with a number of previous studies that have provided data to suggest that individuals who use cannabis before the age of 15 years are substantially more likely to become cannabis dependent (see Chen, O'Brien \& Anthony, 2005; Ehlers et al., 2007; Wagner \& Anthony, 2002). The data from the UCSF study extends those findings and further suggests that survival time for this population was significantly different based on gender with women demonstrating an overall shorter survival time than men. One study of 156 women entering 
treatment for substance dependence reported that women experienced fewer years of regular use of opioids and cannabis, and fewer years of regular alcohol drinking before entering treatment (Hernandez-Avila, Rounsaville \& Kranzler, 2004). These data are consistent with several other studies that have reported "telescoping" (a more rapid progression from onset to the development of clinical problems) of the clinical course of alcoholism in women (Diehl et al., 2007; Ehlers et al., 2004; Randall et al., 1999). The present study may be the first to demonstrate these phenomena in women for the transition between cannabis use and dependence in a community sample.

The prevalence of cannabis dependence criteria have also been reported to differ between men and women. Using data from the NESARC, Agrawal and Lynskey (2007) found that two dependence criteria (quit and problems) showed significant gender heterogeneity and suggested that criteria that serve as indicators of DSM-IV cannabis dependence may not function identically in men and women. In the present study, within the population of individuals who had used cannabis 21 or more time a year, more males endorsed "spending a great deal of time obtaining, using, or recovering from" and "tolerance" to cannabis use. Although no significant gender differences were found in any other of the cannabis dependence criteria almost eighteen percent (17.8\%) of men and $15.6 \%$ of women in the UCSF study who had used cannabis 21 or more time a year reported experiencing cannabis withdrawal. The most common symptoms of withdrawal in the UCSF Family Study were "nervousness", "appetite change" and "trouble sleeping". These three symptoms were also reported to be the most common symptoms of cannabis withdrawal in the COGA study (Wiesbeck et al., 1996). Grant et al. (2006) used latent class analyses to identify 4 classes of cannabis abuse and dependence symptom patterns in data from the National Longitudinal Alcohol Epidemiology Study (NLAES). They found that women in two of the classes were more likely to endorse withdrawal. Lack of gender differences in the present study may be a result of a smaller sample size than the NLAES. Several authors have provided data to suggest that cannabis withdrawal is common in large epidemiological studies such as the NESARC, and that it should be considered as a dependence criterion in DSM (see Agrawal et al., 2008a; Hasin et al., 2008).

\subsection{Withdrawal and untoward side effects associated with cannabis use in the San Francisco Family Study}

Cannabis use has been associated with a number of untoward side effects. In youth under the age of 20, marijuana was the most frequently reported drug in emergency department visits (SAMHSA, 2006). A systematic review of safety studies of medical cannabinoids found that short term use was associated with increased risk of adverse events and that risks associated with long term use were "poorly characterized" (Wang, Collet, Shapiro \& Ware, 2008). Using a case control design, Gruber, Pope, Hudson, \& Yurgelun-Todd, (2003) compared heavy cannabis users to an age-matched control group and found that the users reported negative effects of cannabis on their cognition, career, memory, social life as well as their physical and mental health. Epidemiological studies suggest that cannabis use may be associated with depression (see Degenhardt et al., 2003 for review) and psychosis (see Andreasson, Allebeck, Engstrom \& Rydberg, 1987; Henquet et al., 2005 for review). It is not possible at this time to determine whether these associations are causal or due to common environmental factors that increase the risks for both cannabis use and its untoward effects including symptoms of depression and psychosis. In the UCSF study $29 \%$ of the sample reported depressive symptoms $17.9 \%$ hallucinations, $36.6 \%$ trouble concentrating, and 33\% paranoia that lasted for more than 24 hours, confirming that cannabis use is associated with untoward side effects in this population. Despite these untoward side effects, and the fact that $36 \%$ had wanted to quit using the drug, very few participants had sought treatment for cannabis dependence in this population. These data suggest that further efforts are needed to screen, identify and educate cannabis users whose mental health may potentially benefit from abstinence. 


\subsection{Heritability of cannabis use and symptomatology in the San Francisco Family Study}

Cannabis use, cannabis dependence, the individual cannabis dependence criteria, and several of the untoward side effects of cannabis use were all found to be significantly heritable in the UCSF family population. These findings support previous studies in both female and male twin pairs that have found resemblance and high heritability estimates for use and dependence (Kendler \& Prescott, 1998; Kendler et al., 2000); although, these studies generally have only modest numbers of cannabis dependent participants. A review of the literature has reported that cannabis use estimates of heritability ranged from 0.17 to 0.67 and estimates of heritability of cannabis abuse or dependence at 0.45 to 0.78 (see Agrawal \& Lynskey, 2006). In the UCSF Family Study, estimates of the heritability of having tried and used more than 21 times in a single year $(0.52,0.31)$, were similar to what has been reported in twin studies, but heritability estimates of dependence (0.20) and age at first use (0.22) were somewhat lower.

How genetic and environmental factors may influence the age at which a person first tries cannabis in such a way that it leads to increased risk for cannabis dependence has not been completely formulated. One hypothesis posits that early substance use disrupts the normal course of social and intellectual development leading to an increased risk for a number of social and psychological pathologies including drug addictions (see De Wit, Adlaf, Offord \& Ofborne, 2000; York, 1999). An alternate hypothesis has been forwarded, suggesting that drug addictions and psychopathology are in fact a reflection of a more general underlying susceptibility to "addiction" through psychopathologies and disinhibitory behavior (see Heath \& Martin, 1988; Iacono, Carlson, Malone \& McGue, 2002; McGue, Iacono, Legrand, Malone \& Elkins, 2001: Palmer et al., 2009; Prescott \& Kendler, 1999; Room, Fischer, Hall, Lenton $\&$ Reuter, 2008; Sartor et al., 2009). Although most studies point to age of onset of drug use of as a primarily environmental variable it may represent different constructs at different ages. For instance, very early onset of drug use (before the age of 13) may represent a more general measure of disinhibitory behavior or conduct disorder and as such could potentially be more heritable. In the present study, the number of individuals with very early onset of cannabis use ( $<13 \mathrm{yrs}$ ) was limited and thus the statistical power for evaluation of the heritability of onset of first cannabis use in this age group was limited. As adolescence progresses, cannabis use becomes more common and may be highly influenced by such environmental variables such as peer pressure and social circumstances; whereas, individuals who have not used cannabis, the age of 21 may possess protective factors that may be both environmental (religion, family norms) or genetic (intolerance of smoke). Early cannabis users appear to differ from their non using peers in a variety of ways including: use of tobacco (Agrawal et al., 2008b), performing poorly at school and having low academic expectations, having a problematic relationship with parents, having a history of non conformist behavior and affiliating with drug using peers (see Guxens, Nebot, Ariza \& Ochoa, 2007; Hall \& Degenhardt, 2007). Further studies are needed to disentangle the environmental and heritable factors leading to onset of cannabis use in adolescence.

The current findings suggest that within the UCSF Family Study population that genetic factors highly influence whether an individual in this population may try or use cannabis but that environmental factors may be more influential in determining whether a person becomes dependent. The environmental factors that may influence cannabis dependence in this population are not known but they may be related to the fact that this population was primarily ascertained for alcohol dependence phenotypes. For instance, an individual with genetic risk for cannabis and alcohol dependence may choose alcohol as a primary drug of abuse because of availability or social acceptance of that drug use. Since the UCSF Family Study population had a relatively high economic and education level these factors may also be protective in the development of cannabis dependence among users. A recent study of data from male twins from the Mid Atlantic Twin Registry demonstrated, using retrospective assessments of 
perceived cannabis availability between ages 8 and 25 years, that the latent shared environmental factors responsible for cannabis initiation and abuse could be explained by a measured aspect of the shared environment that had to do with variation in cannabis availability (Gillespie, Neale \& Kendler, 2009). Although drug availability was not measured in the San Francisco Family Study our data certainly do not conflict with the hypothesis that shared environmental variance in availability could explain much of the environmental risk for cannabis dependence.

Several of the symptoms/criteria for DSM-IV cannabis dependence were also found to be heritable in the UCSF family population. The highest heritabilities were found for "craving" for and withdrawal from cannabis usage. These data suggest that these variables may be preferred phenotypes for linkage analyses in this population. The findings that several of the untoward side effects of cannabis use such as depression and paranoia were also in part heritable further suggests that there may be a genetic component to the undesirable as well as the desirable effects of cannabis, a finding that may be useful in designing treatment programs for problematic cannabis users.

The results of this study should be interpreted in the context of several limitations. First, the findings may not generalize to other samples of cannabis users that were ascertained without bias. Second, only retrospective and cross-sectional data on cannabis use and use disorders were assessed. Third, comparisons to other large samples may be limited by differences on a variety of variables including recruitment, as well as a number of genetic and environmentally determined variables. The exclusion criteria for this study eliminated participants reporting serious drug dependence on stimulants, cocaine, or opiates, current diagnosis of schizophrenia, bipolar disorder, or other psychiatric illness involving psychotic symptoms. This exclusion was included to create a more homogeneous sample for genetic analyses. However, this limitation reduces external validity and clinical applicability since the co-occurrence of mental health disorders and substance abuse is common (Kessler et al., 1996). Finally, it should be repeated that the family design cannot fully distinguish between additive genetic and shared environmental influences, and this can lead to positively biased heritability estimates. The inclusion of extended pedigrees containing relative pairs living apart provides some protection against such bias, but is imperfect. Thus, replication of the reported heritability estimates should represent an important priority for future studies.

\section{References}

Agrawal A, Edenberg HJ, Foroud T, Bierut LJ, Dunne G, Hinrichs AL, et al. Association of GABRA2 with drug dependence in the collaborative study of the genetics of alcoholism sample. Behavior Genetics 2006;36:640-650. [PubMed: 16622805]

Agrawal A, Lynskey MT. The genetic epidemiology of cannabis use, abuse and dependence. Addiction 2006;101:801-812. [PubMed: 16696624]

Agrawal A, Lynskey MT. Does gender contribute to heterogeneity in criteria for cannabis abuse and dependence? Results from the national epidemiological survey on alcohol and related conditions. Drug and Alcohol Dependence 2007;88:300-307. [PubMed: 17084563]

Agrawal A, Lynskey MT, Pergadia ML, Bucholz KK, Heath AC, Martin NG, et al. Early cannabis use and DSM-IV nicotine dependence: a twin study. Addiction 2008b;103:1896-1904. [PubMed: 19032539]

Agrawal A, Pergadia ML, Saccone SF, Lynskey MT, Wang JC, Martin NG, et al. An autosomal linkage scan for cannabis use disorders in the nicotine addiction genetics project. Archives of General Psychiatry 2008a;65:713-721. [PubMed: 18519829]

Almasy L, Blangero J. Multipoint quantitative-trait linkage analysis in general pedigrees. American Journal of Human Genetics 1998;62:1198-1211. [PubMed: 9545414]

American Psychiatric Association. Diagnostic and statistical manual of mental disorders (DSM-IV). Washington, DC: Author; 1994. 
Andreasson S, Allebeck P, Engstrom A, Rydberg U. Cannabis and schizophrenia. A longitudinal study of Swedish conscripts. Lancet 1987;2:1483-1486. [PubMed: 2892048]

Anthony JC, Warner LA, Kessler RC. Comparative epidemiology of dependence on tobacco, alcohol, controlled substances, and inhalants: basic findings from the National Comorbididty Survey. Experimental and Clinical Psychopharmacology 1994;2:244-268.

Behrendt S, Wittchen HU, Hofler M, Lieb R, Beesdo K. Transitions from first substance use to substance use disorders in adolescence: is early onset associated with a rapid escalation? Drug and Alcohol Dependence 2009;99:68-78. [PubMed: 18768267]

Bierut LJ, Dinwiddie SH, Begleiter H, Crowe RR, Hesselbrock V, Nurnberger JI Jr, et al. Familial transmission of substance dependence: alcohol, marijuana, cocaine, and habitual smoking: a report from the Collaborative Study on the Genetics of Alcoholism. Archives of General Psychiatry 1998;55:982-988. [PubMed: 9819066]

Blanco C, Ogburn E, Perez de Los CJ, Lujan J, Nunes EV, Grant B, et al. DSM-IV criteria-based clinical subtypes of cannabis use disorders: results from the National Epidemiological Survey on Alcohol and Related Conditions (NESARC). Drug and Alcohol Dependence 2008;96:136-144. [PubMed: 18420357]

Bucholz KK, Cadoret R, Cloninger CR, Dinwiddie SH, Hesselbrock VM, Nurnberger JI Jr, et al. A new, semi-structured psychiatric interview for use in genetic linkage studies: a report on the reliability of the SSAGA. Journal of Studies on Alcohol 1994;55:149-158. [PubMed: 8189735]

Budney AJ, Novy PL, Hughes JR. Marijuana withdrawal among adults seeking treatment for marijuana dependence. Addiction 1999;94:1311-1322. [PubMed: 10615717]

Budney AJ, Vandrey RG, Hughes JR, Thostenson JD, Bursac Z. Comparison of cannabis and tobacco withdrawal: severity and contribution to relapse. J Subst.Abuse Treat 2008;35:362-368. [PubMed: 18342479]

Chen CY, O'Brien MS, Anthony JC. Who becomes cannabis dependent soon after onset of use? Epidemiological evidence from the United States: 2000-2001. Drug and Alcohol Dependence 2005;79:11-22. [PubMed: 15943940]

Chen CY, Storr CL, Anthony JC. Early-onset drug use and risk for drug dependence problems. Addictive Behaviors 2009;34:319-322. [PubMed: 19022584]

Compton WM, Grant BF, Colliver JD, Glantz MD, Stinson FS. Prevalence of marijuana use disorders in the United States: 1991-1992 and 2001-2002. Journal of the American Medical Association 2004;291:2114-2121. [PubMed: 15126440]

Cornelius JR, Chung T, Martin C, Wood DS, Clark DB. Cannabis withdrawal is common among treatment-seeking adolescents with cannabis dependence and major depression, and is associated with rapid relapse to dependence. Addictive Behaviors 2008;33:1500-1505. [PubMed: 18313860]

Cripe L, Andelfinger G, Martin LJ, Shooner K, Benson DW. Bicuspid aortic valve is heritable. J Am Coll.Cardiol 2004;44:138-143. [PubMed: 15234422]

Degenhardt L, Chiu WT, Conway K, Dierker L, Glantz M, Kalaydjian A, et al. Does the 'gateway' matter? Associations between the order of drug use initiation and the development of drug dependence in the National Comorbidity Study Replication. Psychological Medicine 2009;39:157-167. [PubMed: 18466664]

Degenhardt L, Hall W, Lynskey M. Exploring the association between cannabis use and depression. Addiction 2003;98:1493-1504. [PubMed: 14616175]

De Wit DJ, Adlaf EM, Offord DR, Ogborne AC. Age at first alcohol use: a risk factor for the development of alcohol disorders. American Journal of Psychiatry 2000;157:745-750. [PubMed: 10784467]

Diehl A, Croissant B, Batra A, Mundle G, Nakovics H, Mann K. Alcoholism in women: is it different in onset and outcome compared to men? European Archives of Psychiatry and Clinical Neuroscience 2007;257:344-351. [PubMed: 17629733]

Ehlers CL, Slutske WS, Gilder DA, Lau P, Wilhelmsen KC. Age at first intoxication and alcohol use disorders in Southwest California Indians. Alcoholism: Clinical and Experimental Research 2006;30:1856-1865.

Ehlers CL, Wall TL, Betancourt M, Gilder DA. The clinical course of alcoholism in 243 Mission Indians. American Journal of Psychiatry 2004;161:1204-1210. [PubMed: 15229052] 
Ehlers CL, Wall TL, Corey L, Lau P, Gilder DA, Wilhelmsen K. Heritability of illicit drug use and transition to dependence in Southwest California Indians. Psychiatric Genetics 2007;17:171-176. [PubMed: 17417061]

Fergusson DM, Horwood LJ. Does cannabis use encourage other forms of illicit drug use? Addiction 2000;95:505-520. [PubMed: 10829327]

Fisher BA, Ghuran A, Vadamalai V, Antonios TF. Cardiovascular complications induced by cannabis smoking: a case report and review of the literature. Emergency Medicine Journal 2005;22:679-680. [PubMed: 16113206]

Gfroerer J. Correlation between drug use by teenagers and drug use by older family members. American Journal of Drug and Alcohol Abuse 1987;13:95-108. [PubMed: 3687887]

Gillespie NA, Neale MC, Kendler KS. Pathways to cannabis abuse: a multistage model from cannabis availability, cannabis initiation and progression to abuse. Addiction 2009;104:430-438. [PubMed: 19207351]

Grant BF, Pickering R. The relationship between cannabis use and DSM-IV cannabis abuse and dependence: results from the National Longitudinal Alcohol Epidemiologic Survey. Journal of Substance Abuse 1998;10:255-264. [PubMed: 10689658]

Grant JD, Scherrer JF, Neuman RJ, Todorov AA, Price RK, Bucholz KK. A comparison of the latent class structure of cannabis problems among adult men and women who have used cannabis repeatedly. Addiction 2006;101:1133-1142. [PubMed: 16869843]

Gruber AJ, Pope HG, Hudson JI, Yurgelun-Todd D. Attributes of long-term heavy cannabis users: a casecontrol study. Psychological Medicine 2003;33:1415-1422. [PubMed: 14672250]

Guxens M, Nebot M, Ariza C, Ochoa D. Factors associated with the onset of cannabis use: a systematic review of cohort studies. Gaceta Sanitaria 2007;21:252-260. [PubMed: 17565903]

Hall W, Degenhardt L. Prevalence and correlates of cannabis use in developed and developing countries. Current Opinion in Psychiatry 2007;20:393-397. [PubMed: 17551355]

Hall WD, Degenhardt L, Teesson M. Cannabis use and psychotic disorders: an update. Drug and Alcohol Review 2004;23:433-443. [PubMed: 15763748]

Hashibe M, Straif K, Tashkin DP, Morgenstern H, Greenland S, Zhang ZF. Epidemiologic review of marijuana use and cancer risk. Alcohol 2005;35:265-275. [PubMed: 16054989]

Hasin DS, Keyes KM, Alderson D, Wang S, Aharonovich E, Grant BF. Cannabis withdrawal in the United States: Results from NESARC. Journal of Clinical Psychiatry 2008;69:1354-1363. [PubMed: 19012815]

Heath AC, Martin NG. Teenage alcohol use in the Australian twin register: genetic and social determinants of starting to drink. Alcoholism: Clinical and Experimental Research 1988;12:735741.

Heishman SJ, Evans RJ, Singleton EG, Levin KH, Copersino ML, Gorelick DA. Reliability and validity of a short form of the Marijuana Craving Questionnaire. Drug and Alcohol Dependence 2009;102:3540. [PubMed: 19217724]

Henquet C, Krabbendam L, Spauwen J, Kaplan C, Lieb R, Wittchen HU, et al. Prospective cohort study of cannabis use, predisposition for psychosis, and psychotic symptoms in young people. BMJ: British Medical Journal 2005;330:11.

Hernandez-Avila CA, Rounsaville BJ, Kranzler HR. Opioid-, cannabis-and alcohol-dependent women show more rapid progression to substance abuse treatment. Drug and Alcohol Dependence 2004;74:265-272. [PubMed: 15194204]

Hopfer CJ, Stallings MC, Hewitt JK, Crowley TJ. Family transmission of marijuana use, abuse, and dependence. Journal of the American Academy of Child and Adolescent Psychiatry 2003;42:834841. [PubMed: 12819443]

Iacono WG, Carlson SR, Malone SM, McGue M. P3 event-related potential amplitude and the risk for disinhibitory disorders in adolescent boys. Archives of General Psychiatry 2002;59:750-757. [PubMed: 12150652]

Kandel DB, Chen K. Types of marijuana users by longitudinal course. Journal of Studies on Alcohol 2000;61:367-378. [PubMed: 10807207] 
Kendler KS, Karkowski LM, Neale MC, Prescott CA. Illicit psychoactive substance use, heavy use, abuse, and dependence in a US population-based sample of male twins. Archives of General Psychiatry 2000;57:261-269. [PubMed: 10711912]

Kendler KS, Prescott CA. Cannabis use, abuse, and dependence in a population-based sample of female twins. American Journal of Psychiatry 1998;155:1016-1022. [PubMed: 9699687]

Kessler RC, Nelson CB, McGonagle KA, Edlund MJ, Frank RG, Leaf PJ. The epidemiology of cooccurring addictive and mental disorders: implications for prevention and service utilization. Am J Orthopsychiatry 1996;66:17-31. [PubMed: 8720638]

Lynskey M, Hall W. The effects of adolescent cannabis use on educational attainment: a review. Addiction 2000;95:1621-1630. [PubMed: 11219366]

Lynskey M, Heath AC, Bucholz KK, Slutske WS, Madden PA, Nelson EC, et al. Escalation of drug use in early-onset cannabis users vs co-twin controls. Journal of the American Medical Association 2003;289:427-433. [PubMed: 12533121]

Maes HH, Woodard CE, Murrelle L, Meyer JM, Silberg JL, Hewitt JK, et al. Tobacco, alcohol and drug use in eight- to sixteen-year-old twins: the Virginia Twin Study of Adolescent Behavioral Development. Journal of Studies on Alcohol 1999;60:293-305. [PubMed: 10371255]

Maxwell JC. Are we becoming more alike? Comparison of substance use in Australia and the United States as seen in the 1995, 1998, 2001 and 2004 national household surveys. Drug and Alcohol Review 2008;27:473-481. [PubMed: 18696294]

McCrady, BS.; Epstein, EE. Addictions: A Comprehensive Guidebook. New York: Oxford University Press; 1999.

McGue M, Elkins I, Iacono WG. Genetic and environmental influences on adolescent substance use and abuse. American Journal of Medical Genetics, Part B: Neuropsychiatric Genetics 2000;96:671-677.

McGue M, Iacono WG, Legrand LN, Malone S, Elkins I. Origins and consequences of age at first drink I. Associations with substance-use disorders, disinhibitory behavior and psychopathology, and P3 amplitude. Alcoholism: Clinical and Experimental Research 2001;25:1156-1165.

McRae AL, Hedden SL, Malcolm RJ, Carter RE, Brady KT. Characteristics of cocaine- and marijuanadependent subjects presenting for medication treatment trials. Addictive Behaviors 2007;32:14331440. [PubMed: 17150310]

Meller WH, Rinehart R, Cadoret RJ, Troughton E. Specific familial transmission in substance abuse. International Journal of the Addictions 1988;23:1029-1039. [PubMed: 3235221]

Merikangas KR, Stolar M, Stevens DE, Goulet J, Preisig MA, Fenton B, et al. Familial transmission of substance use disorders. Archives of General Psychiatry 1998;55:973-979. [PubMed: 9819065]

Miles DR, van den Bree MB, Gupman AE, Newlin DB, Glantz MD, Pickens RW. A twin study on sensation seeking, risk taking behavior and marijuana use. Drug and Alcohol Dependence 2001;62:57-68. [PubMed: 11173168]

Mittleman MA, Lewis RA, Maclure M, Sherwood JB, Muller JE. Triggering myocardial infarction by marijuana. Circulation 2001;103:2805-2809. [PubMed: 11401936]

Palmer RH, Young SE, Hopfer CJ, Corley RP, Stallings MC, Crowley TJ, et al. Developmental epidemiology of drug use and abuse in adolescence and young adulthood: Evidence of generalized risk. Drug and Alcohol Dependence 2009;102:78-87. [PubMed: 19250776]

Pope HG Jr, Gruber AJ, Hudson JI, Huestis MA, Yurgelun-Todd D. Neuropsychological performance in long-term cannabis users. Archives of General Psychiatry 2001;58:909-915. [PubMed: 11576028]

Prescott CA, Kendler KS. Age at first drink and risk for alcoholism: a noncausal association. Alcoholism: Clinical and Experimental Research 1999;23:101-107.

Randall CL, Roberts JS, Del Boca FK, Carroll KM, Connors GJ, Mattson ME. Telescoping of landmark events associated with drinking: a gender comparison. Journal of Studies on Alcohol 1999;60:252260. [PubMed: 10091964]

Rhee SH, Hewitt JK, Young SE, Corley RP, Crowley TJ, Stallings MC. Genetic and environmental influences on substance initiation, use, and problem use in adolescents. Archives of General Psychiatry 2003;60:1256-1264. [PubMed: 14662558]

Room, R.; Fischer, B.; Hall, W.; Lenton, S.; Reuter, P. Cannabis policy: Moving beyond stalemate. Oxford: The Beckley Foundation; 2008. 
Sartor CE, Agrawal A, Lynskey MT, Bucholz KK, Madden PA, Heath AC. Common genetic influences on the timing of first use for alcohol, cigarettes, and cannabis in young African-American women. Drug and Alcohol Dependence 2009;102:49-55. [PubMed: 19261395]

Schuckit, MA. Drug and Alcohol Abuse. Vol. 6th ed.. New York: Springer Science+Business Media, Inc.; 2006.

Seaton KL, Cornell JL, Wilhelmsen KC, Vieten C. Effective strategies for recruiting families ascertained through alcoholic probands. Alcoholism: Clinical and Experimental Research 2004;28:78-84.

Sharma BP. Cannabis and its users in Nepal. British Journal of Psychiatry 1975;127:550-552. [PubMed: 1236656]

Solowij N, Stephens RS, Roffman RA, Babor T, Kadden R, Miller M, et al. Cognitive functioning of long-term heavy cannabis users seeking treatment. Journal of the American Medical Association 2002;287:1123-1131. [PubMed: 11879109]

Southwest Foundation for Biomedical Research [S.F.B.R.]. Sequential Oligogenic Linkage Analysis Routines [SOLAR]. 2009. [On-line]. Available: http://solar.sfbrgenetics.org/

Stinson FS, Grant BF, Dawson DA, Ruan WJ, Huang B, Saha T. Comorbidity between DSM-IV alcohol and specific drug use disorders in the United States: results from the National Epidemiologic Survey on Alcohol and Related Conditions. Drug and Alcohol Dependence 2005;80:105-116. [PubMed: 16157233]

Stinson FS, Ruan WJ, Pickering R, Grant BF. Cannabis use disorders in the USA: Prevalence, correlates and co-morbidity. Psychological Medicine 2006;36:1447-1460. [PubMed: 16854249]

Substance Abuse and Mental Health Services Administration [SAMHSA]. Results from the 2003 national survey on drug use and health: National findings. Rockville, MD: U.S. Department of Health and Human Services, Office of Applied Studies; 2003. (Rep. No. NSDUH Series H-25, DHHS Publication No. SMA 04-3964)

Substance Abuse and Mental Health Services Administration [SAMHSA]. Drug Abuse Warning Network, 2004: National estimates of drug-related emergency department visits. Rockville, MD: U.S. Department of Health and Human Services, Office of Applied Studies; 2006. (Rep. No. DHHS Publication No. (SMA) 06-4143 DAWN Series D-28)

Swift W, Coffey C, Carlin JB, Degenhardt L, Patton GC. Adolescent cannabis users at 24 years: trajectories to regular weekly use and dependence in young adulthood. Addiction 2008;103:13611370. [PubMed: 18855826]

Swift W, Hall W, Teesson M. Cannabis use and dependence among Australian adults: results from the National Survey of Mental Health and Wellbeing. Addiction 2001;96:737-748. [PubMed: 11331032]

Tashkin DP. Smoked marijuana as a cause of lung injury. Monaldi Archives for Chest Disease 2005;63:93-100. [PubMed: 16128224]

Taylor DR, Poulton R, Moffitt TE, Ramankutty P, Sears MR. The respiratory effects of cannabis dependence in young adults. Addiction 2000;95:1669-1677. [PubMed: 11219370]

Tsuang MT, Lyons MJ, Harley RM, Xian H, Eisen S, Goldberg J, et al. Genetic and environmental influences on transitions in drug use. Behavior Genetics 1999;29:473-479. [PubMed: 10857252]

Tsuang MT, Lyons MJ, Meyer JM, Doyle T, Eisen SA, Goldberg J, et al. Co-occurrence of abuse of different drugs in men: the role of drug-specific and shared vulnerabilities. Archives of General Psychiatry 1998;55:967-972. [PubMed: 9819064]

van den Bree MB, Johnson EO, Neale MC, Svikis DS, McGue M, Pickens RW. Genetic analysis of diagnostic systems of alcoholism in males. Biological Psychiatry 1998;43:139-145. [PubMed: 9474446]

Vieten C, Seaton KL, Feiler HS, Wilhelmsen KC. The University of California, San Francisco Family Alcoholism Study. I. Design, methods, and demographics. Alcoholism: Clinical and Experimental Research 2004;28:1509-1516.

Wagner FA, Anthony JC. From first drug use to drug dependence; developmental periods of risk for dependence upon marijuana, cocaine, and alcohol. Neuropsychopharmacology 2002;26:479-488. [PubMed: 11927172]

Wagner FA, Anthony JC. Male-female differences in the risk of progression from first use to dependence upon cannabis, cocaine, and alcohol. Drug and Alcohol Dependence 2007;86:191-198. [PubMed: 17029825] 
Wang T, Collet JP, Shapiro S, Ware MA. Adverse effects of medical cannabinoids: a systematic review. Canadian Medical Association Journal 2008;178:1669-1678. [PubMed: 18559804]

Wiesbeck GA, Schuckit MA, Kalmijn JA, Tipp JE, Bucholz KK, Smith TL. An evaluation of the history of a marijuana withdrawal syndrome in a large population. Addiction 1996;91:1469-1478. [PubMed: 8917915]

Wilhelmsen KC, Ehlers C. Heritability of substance dependence in a Native American population. Psychiatric Genetics 2005;15:101-107. [PubMed: 15900224]

York JL. Clinical significance of alcohol intake parameters at initiation of drinking. Alcohol 1999;19:9799. [PubMed: 10487393]

\section{Acknowledgments}

The authors thank Shirley Sanchez for assistance in proof-reading and editing the manuscript.

Role of Funding Sources

Supported in part by funds from the State of California for medical research on alcohol and substance abuse through the University of California at San Francisco. Additional support was provided by the Ernest Gallo Clinic and Research Center to KCW and AA010201 and U54 RR0250204 to CLE. 


\section{Survival analysis of age of first cannabis use to the development of cannabis dependence}
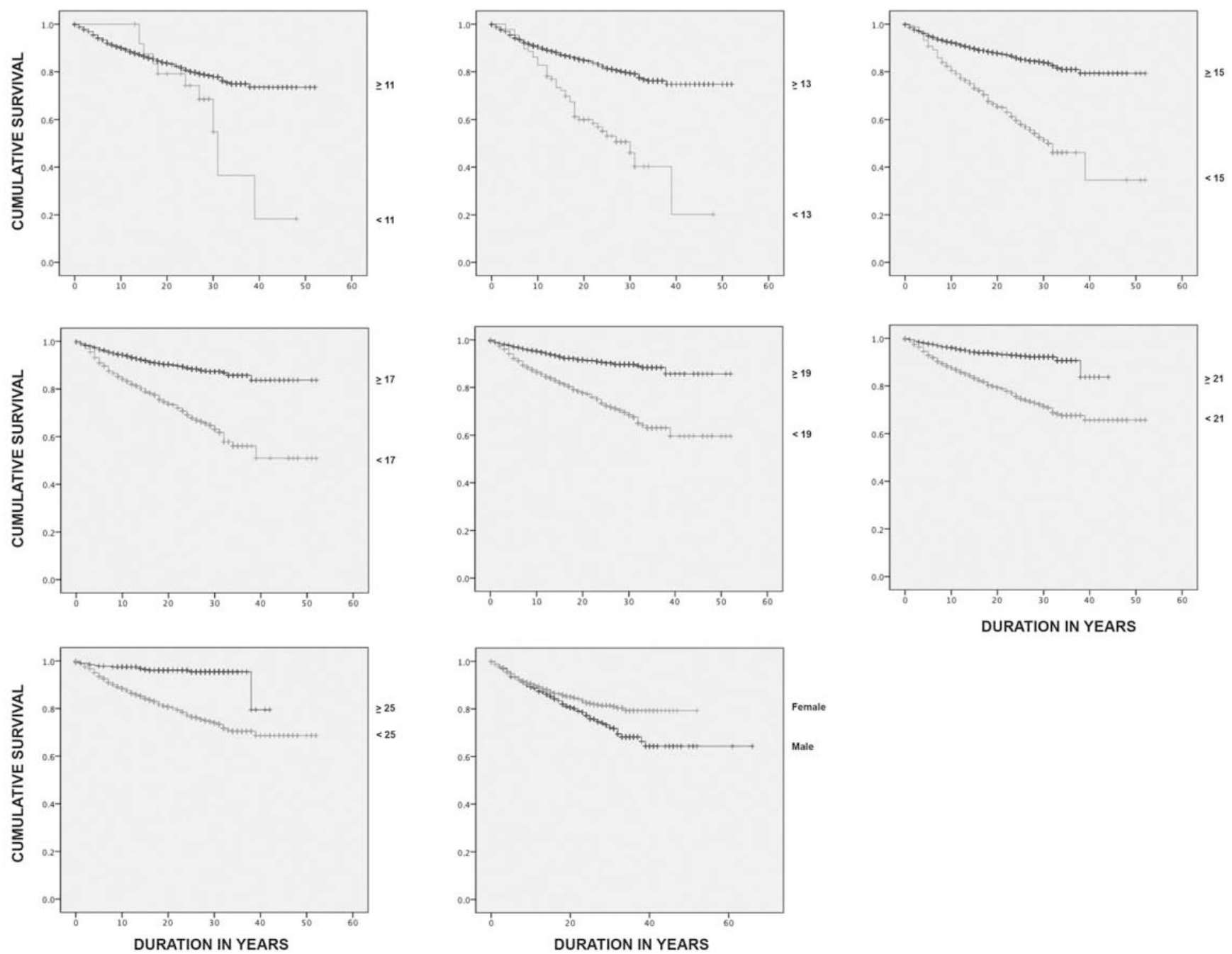

Figure 1.

The following graphs exhibit the cumulative survival rates between two groups of subjects: those who first used cannabis under age $(13,15,17,19,21,25)$ group $(\diamond)$ versus those whose first used cannabis over age $(13,15,17,19,21,25)$ group $(\diamond)$ respectively. The cumulative survival rate is the proportion of subjects within the group who survives (i.e. not developing cannabis dependence) at different points in time after the subjects' first exposure to cannabis. The survival curves of the older cannabis consumption group $(\diamond)$ are consistently above those of the younger group $(\diamond)$, and their survival curves diverge farther and farther apart as time progresses. These graphs clearly indicate that subjects that use cannabis at a later age are more likely to survive without cannabis dependence than those consume at an earlier age. 


\begin{tabular}{|c|c|c|c|c|c|c|c|}
\hline $\begin{array}{l}N \\
0 \\
\frac{0}{0} \\
\stackrel{\sigma}{\sigma}\end{array}$ & 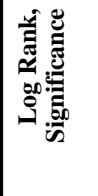 & $\begin{array}{l}\vec{b} \\
\dot{0} \\
\dot{0} \\
\dot{2} \\
2 \\
\dot{0} \\
\dot{\sigma} \\
\dot{\gamma}\end{array}$ & $\begin{array}{l}\bar{b} \\
\dot{0} \\
v \\
2 \\
a \\
\dot{0} \\
0 \\
0 \\
0\end{array}$ & 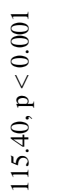 & $\begin{array}{l}\bar{b} \\
\dot{0} \\
v \\
2 \\
0 \\
0 \\
\dot{0} \\
\dot{0}\end{array}$ & $\begin{array}{l}\bar{b} \\
0 \\
0 \\
0 \\
0 \\
0 \\
0 \\
0 \\
0\end{array}$ & 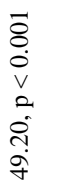 \\
\hline \multirow{6}{*}{ 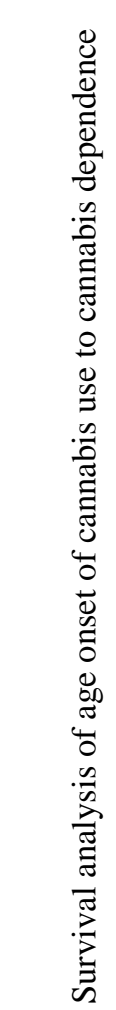 } & 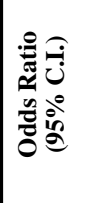 & 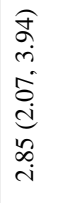 & $\begin{array}{l}\widehat{r} \\
\dot{+} \\
\hat{0} \\
\dot{0} \\
\hat{j} \\
\hat{n}\end{array}$ & 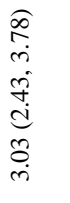 & 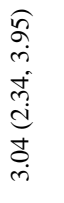 & 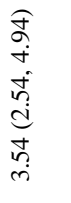 & 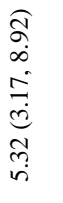 \\
\hline & $\frac{d}{2}$ & 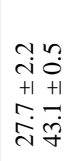 & 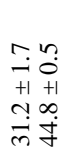 & 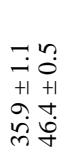 & 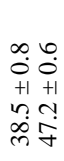 & 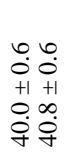 & 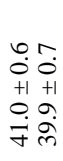 \\
\hline & 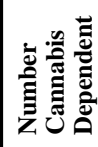 & જ & 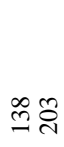 & 곤 & ิำ & ల్లి & ले \\
\hline & 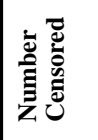 & 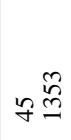 & $\stackrel{2}{\circ}$ & \&ুo & 赵茴 & సু子 & ڤ̊ \\
\hline & 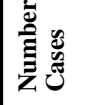 & $\infty \tilde{\sigma}$ & 苂 & $\stackrel{2}{ }$ & 홍 & స్తి & ఫొర \\
\hline & 总 & $\begin{array}{l}\dot{s} \\
\stackrel{m}{\frac{m}{v}} \frac{m}{\wedge 1}\end{array}$ & $\begin{array}{l}\dot{s} \\
\stackrel{\vec{\Delta}}{v} \frac{n}{\wedge 1}\end{array}$ & 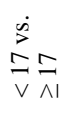 & $\begin{array}{l}\dot{s} \\
\dot{\vec{\sigma}} \\
\overrightarrow{\mathrm{v}}\end{array}$ & $\begin{array}{l}\dot{s} \\
\vec{\sim} \vec{\sim} \\
\vec{v} \wedge\end{array}$ &  \\
\hline
\end{tabular}

Addict Behav. Author manuscript; available in PMC 2011 February 1. 


\begin{tabular}{|c|c|c|c|c|c|c|c|c|c|}
\hline 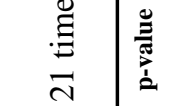 & 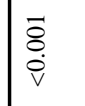 & $\mid \begin{array}{l}\infty \\
0 \\
0\end{array}$ & $\mid \vec{r}$ & : & \begin{tabular}{|c}
0 \\
0 \\
0
\end{tabular} & 是 & \begin{tabular}{|l}
$\infty$ \\
$\stackrel{0}{0}$ \\
\end{tabular} & ปี & $\begin{array}{l}\infty \\
\stackrel{0}{0}\end{array}$ \\
\hline  & 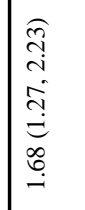 & $\mid \begin{array}{l}\widehat{\mathcal{f}} \\
0 \\
0 \\
0 \\
0 \\
0 \\
0 \\
0\end{array}$ & 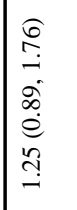 & 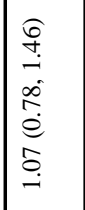 & 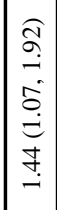 & 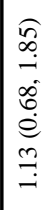 & 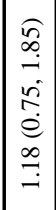 & 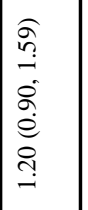 &  \\
\hline $\begin{array}{l}\frac{\pi}{0} \\
\frac{0}{3}\end{array}$ & 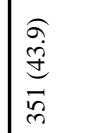 &  & \begin{tabular}{|l}
$\widehat{a}$ \\
$\bar{d}$ \\
$\underline{a}$ \\
$\underline{\underline{a}}$
\end{tabular} & 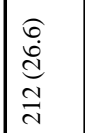 & 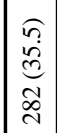 & 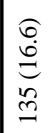 & \begin{tabular}{|l|}
0 \\
0 \\
0 \\
0 \\
0 \\
0 \\
0
\end{tabular} & 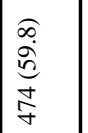 & $\begin{array}{l}\widehat{\sigma} \\
\stackrel{a}{d} \\
\text { ปे }\end{array}$ \\
\hline 这 & \begin{tabular}{l}
$\widehat{c}$ \\
$\infty$ \\
$\infty$ \\
$\infty$ \\
$\infty$ \\
$\infty$ \\
\hdashline
\end{tabular} & 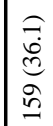 & 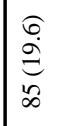 & 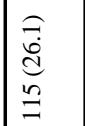 & \begin{tabular}{|l|}
$\widehat{0}$ \\
$\dot{0}$ \\
0 \\
$o$ \\
0
\end{tabular} & 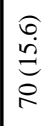 & 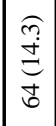 & 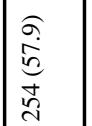 & $\begin{array}{l}a \\
a \\
d \\
d \\
a \\
a\end{array}$ \\
\hline 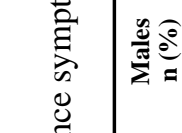 & $\begin{array}{l}\hat{\sigma} \\
\stackrel{\dot{\omega}}{\infty} \\
\infty \\
\stackrel{\infty}{\infty}\end{array}$ & $\begin{array}{l}n \\
\tilde{n} \\
\tilde{c} \\
\tilde{m}\end{array}$ & \begin{tabular}{|l}
$\widehat{\sigma}$ \\
$\stackrel{d}{d}$ \\
$\infty$ \\
$\infty$
\end{tabular} & $\mid \begin{array}{l}\widehat{a} \\
\stackrel{a}{a} \\
a\end{array}$ & 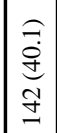 & 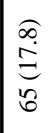 & \begin{tabular}{|l|}
0 \\
0 \\
$\stackrel{\infty}{0}$ \\
0 \\
0
\end{tabular} & \begin{tabular}{|l}
$\widehat{\widehat{i}}$ \\
d. \\
ते
\end{tabular} & $\mid \begin{array}{l}\widehat{\sigma} \\
\stackrel{d}{d} \\
\alpha\end{array}$ \\
\hline 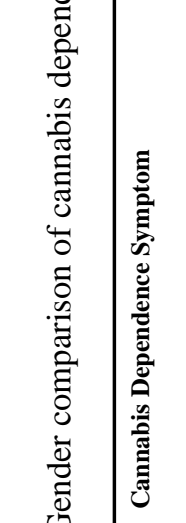 & 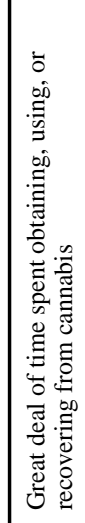 & 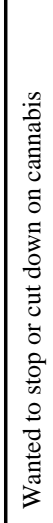 & 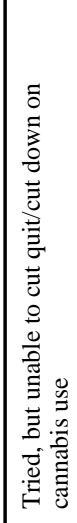 &  & 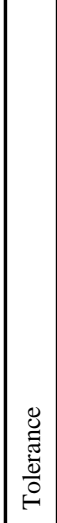 & 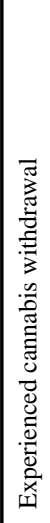 & 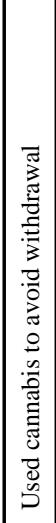 & 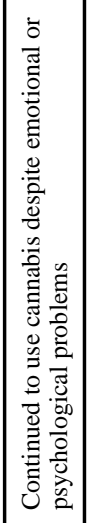 &  \\
\hline
\end{tabular}

Addict Behav. Author manuscript; available in PMC 2011 February 1. 
Table 4

Psychiatric symptoms experienced as a consequence of cannabis use

\begin{tabular}{|l|c|}
\hline Psychiatric Symptom & n (\%) \\
\hline Decreased contact with family or friends & $319(40.2)$ \\
\hline Trouble concentrating for $>24$ hours & $290(36.6)$ \\
\hline Paranoid/suspicious of people for $>24$ hours & $261(32.8)$ \\
\hline Depressed/uninterested in things for $>24$ hours & $231(29.1)$ \\
\hline Hallucinations & $142(17.9)$ \\
\hline Withdrawal Symptom & \\
\hline Nervous, tense, restless or irritable & $197(24.2)$ \\
\hline Appetite Change or Weight Change & $165(20.3)$ \\
\hline Trouble sleeping & $121(14.9)$ \\
\hline Trembling/Twitching & $30(3.7)$ \\
\hline Sweating/Fever & $24(2.9)$ \\
\hline Diarrhea/Stomach aches & \\
\hline Nausea/Vomiting & \\
\hline
\end{tabular}


Table 5

Heritability of Cannabis-Related Phenotypes

\begin{tabular}{|c|c|c|c|c|}
\hline Trait & Age (p) & $\operatorname{Sex}(p)$ & $\mathbf{h}^{2}$ & $\mathbf{p}$ \\
\hline Used cannabis & $<0.0001$ & & 0.52 & $<0.0001$ \\
\hline Used $\geq 21$ times year & $<0.0001$ & 0.009 & 0.31 & $<0.0001$ \\
\hline DSM-IV cannabis dependence & $<0.0001$ & 0.048 & 0.20 & $<0.0001$ \\
\hline Age at first use & $<0.0001$ & $<0.0001$ & 0.22 & 0.002 \\
\hline \multicolumn{5}{|l|}{ DSM-IV Symptoms } \\
\hline Emotional/psychological problems & $<0.0001$ & 0.131 & 0.23 & $<0.0001$ \\
\hline Cannabis avoid withdrawal & $<0.0001$ & 0.014 & 0.25 & 0.0001 \\
\hline Cannabis reduced activities & $<0.0001$ & & 0.21 & $<0.0001$ \\
\hline Great deal of time using & $<0.0001$ & 0.002 & 0.29 & $<0.0001$ \\
\hline Multiple withdrawal symptoms & $<0.0001$ & 0.043 & 0.26 & $<0.0001$ \\
\hline Tried stop cannabis & $<0.0001$ & 0.249 & 0.23 & $<0.0001$ \\
\hline Want stop cannabis & $<0.0001$ & 0.007 & 0.15 & 0.002 \\
\hline Tolerance & $<0.0001$ & 0.637 & 0.25 & $<0.0001$ \\
\hline Used more than intended & $<0.0001$ & & 0.11 & 0.01 \\
\hline \multicolumn{5}{|l|}{ Cannabis Consequences } \\
\hline Cannabis depressed $>$ a day & $<0.0001$ & 0.03 & 0.16 & 0.0006 \\
\hline Cannabis concentrating $>$ a day & $<0.0001$ & & 0.19 & $<0.0001$ \\
\hline Cannabis paranoid $>$ a day & $<0.0001$ & & 0.11 & 0.008 \\
\hline Cannabis "craving" & $<0.0001$ & & 0.36 & $<0.0001$ \\
\hline Cannabis nervous during withdrawal & $<0.0001$ & 0.28 & 0.30 & $<0.0001$ \\
\hline Cannabis hallucinations $>$ a day & $<0.0001$ & & 0.07 & 0.07 \\
\hline
\end{tabular}

